\title{
Intramedullary versus Extramedullary Tibial Cutting Guides in Total Knee Procedures: Our Experience at King Abdulaziz University Hospital in Saudi Arabia
}

\author{
Lutf A. Abumunaser, MD, FACHARTZ, Amre S. Hamdi, MD, FRCSC, and \\ Faeq M.W. Sawaf', MD
}

Department of Surgery, Division of Orthopedic, Faculty of Medicine, King Abdulaziz University, Jeddah and 'Department of Surgery, Division of Orthopedic, Faculty of Medicine, King Abdulaziz University, Rabigh

\section{Correspondence}

Dr. Lutf A. Abumunaser

P.O. Box 80215, Jeddah 21589, Saudi Arabia

e.M: labumunaser@gmail.com

Submission: 22 July 2015

Accepted: $\quad 05$ Nov. 2015

\section{Citation}

Abumunaser LA, Hamdi AS, Sawaf FM. Intramedullary versus extramedullary tibial cutting guides in total knee procedures: our experience at King Abdulaziz University Hospital in Saudi Arabia. JKAU Med Sci 2016; 23 (1): 23-28. DOl: 10.4197/Med. 23.1.4

\begin{abstract}
The tibial component alignment is believed to be a key factor for the survivorship of total knee arthroplasty. But there is still controversy whether intramedullary or extramedullary cutting guidance is more accurate for tibial component alignment. This retrospective study aims to compare the accuracy of intramedullary and extramedullary tibial cutting guides in Total knee replacement. 88 Total knee replacements were carried out in 60 patients between January 2013 and April 2015. Out of 88 procedures 38 were in the intramedullary group and 50 in the extramedullary group. The tibial component alignment was evaluated by measuring the laterally formed angle between the transverse axis of the tibial component and the mechanical axis of the tibia. The tibial component angle was measured on postoperative long film X-rays of lower limb. The mean tibial component angle \pm SD was $91.22 \pm$ 2.74 for the intramedullary group, and $91.95 \pm 2.34(p=0.184)$ for the extramedullary group. The normal tibial component angle values (88-92) was found in $52.6 \%$ in the intramedullary group and in $48 \%$ of the extramedullary group ( $p=0.188$ ). No statistically significant difference was found between the intramedullary and extramedullary tibial cutting guides with regard to the accuracy of the normal tibial component alignment.
\end{abstract}

\section{Keywords}

Total knee replacement; Tibial cutting guide; Intramedullary, Extramedullary

\section{Introduction}

otal knee replacement (TKR) is considered one of the most common and successful reconstructive surgeries, providing satisfactory long term outcomes.
A correct alignment of the prosthesis plays a major role for the longevity and success of the TKR procedure. The debate on the optimal technique of femoral alignment is near resolution ${ }^{[1]}$; however, there is still contention about whether the intramedullary or extramedullary 
alignment guide provides better reliability and accuracy for the tibial cutting angle $\mathrm{e}^{[1-4]}$.

Angle values of $88-92^{\circ}$ between the tibial plateau and the mechanical axis of the tibia in the coronal plane were considered normal and have been correlated by several authors with better results and longer survival of the implant ${ }^{[5-7]}$.

We conducted the present study with the aim of comparing the accuracy of intramedullary and extramedullary guides used for tibial cutting in TKR, and whether one of them might be superior to the other.

\section{Materials and Methods}

This retrospective comparative study was performed at a single institute at which we reviewed the electronic medical records and digital radiographs of 60 patients who underwent TKR between January 2013 and April 2015 at King Abdulaziz University Hospital, Jeddah, Saudi Arabia. The study was approved by the ethical committee for human research in our institution (Reference No. 200-15). Eighty-eight TKR`s were carried out in 60 patients in the current study. 48 patients were female and 12 were male, with a mean age of $65.37 \pm$ 9.99 years. Fifty-nine $(67.0 \%)$ were unilateral and 29 (33\%) bilateral. The diagnosis was primary gonarthrosis in 82 patients, while the remaining six were diagnosed to have other arthritis. The patients were divided into two groups; one group of patients in whom an extramedullary tibial alignment guide was used, and another group in whom the intramedullary was used. All patients had pre-and postoperative radiographic views including anteroposterior, lateral, and long standing film of the lower limb.

Both extramedullary and intramedullary techniques were performed according to the manufacturer's instructions. The extramedullary guiding rod was aligned to be parallel to the axis of the tibia, with the reference points proximally being the medial third of the tibial tubercle and medial margin of the lateral intercondylar eminence with the extremities of the cutting surface against the anterior cortex, and distally the center of the talus with shifting the guide rod $3 \mathrm{~mm}$ medially. The entry point of the intramedullary guide was determined during the preoperative planning (using the preoperative long standing film of the lower limb) for the center of the mechanical axis. This was almost centered on the tibial spine in both medial/lateral and anterior/posterior aspect. The guide should pass just distal to the isthmus level. The slope angle was usually 3 degrees for the cruciate retaining $(C R)$ and 0 degree for the cruciate substitution (CS).

The alignment of the tibial component in the coronal plane was evaluated by means of the anteroposterior view of long standing radiograph of the lower limb. The laterally formed angle between the transverse axis of the tibial component and the mechanical axis of tibia is the tibial component angle (TCA) (Fig. 1). The TCA was measured digitally as we use only digital radiographs (sectra, isd7 system) in our hospital. Values of $88-92^{\circ}$ were considered normal,

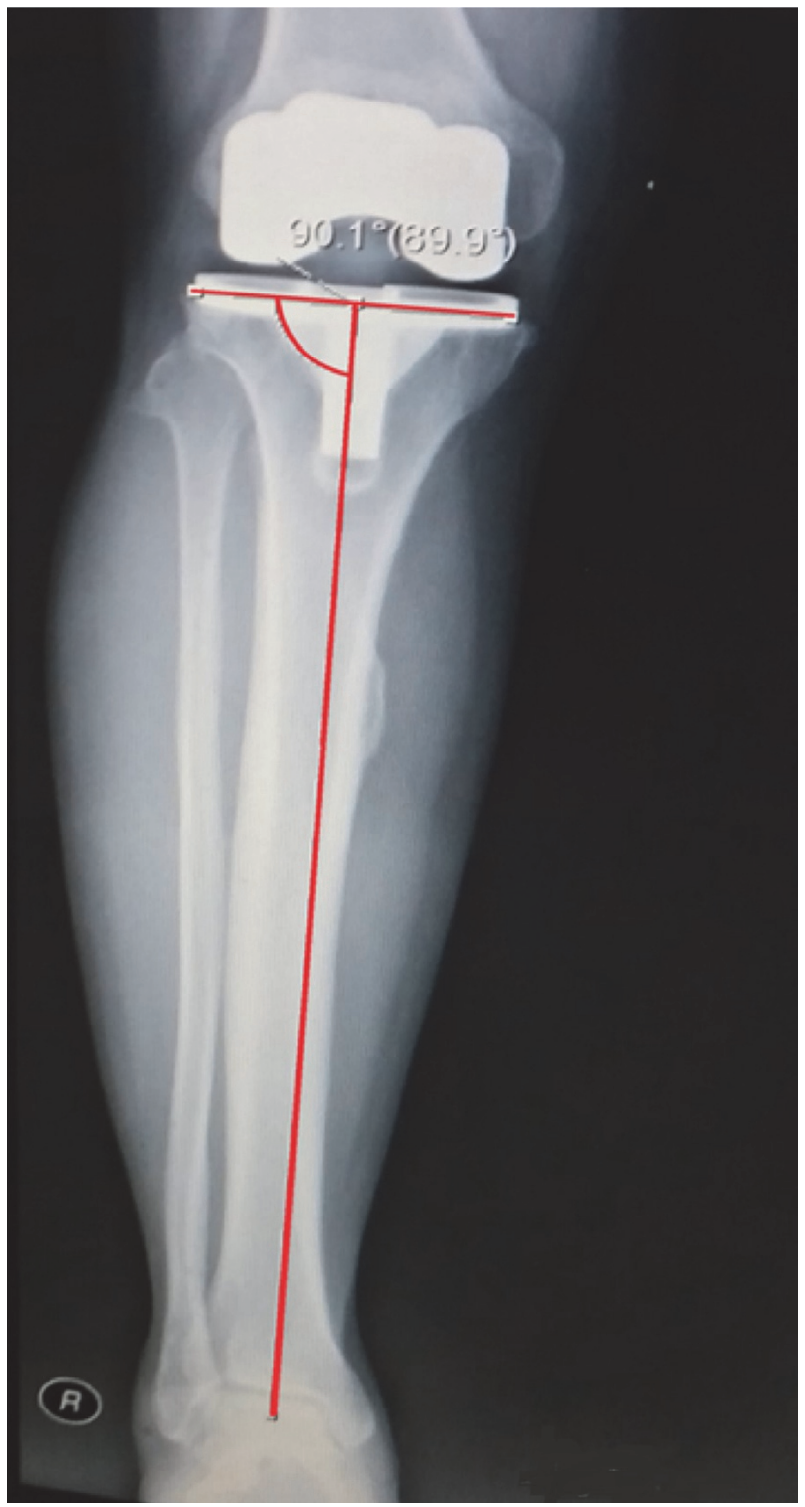

Figure 1. X-ray showing measurement of the tibial component angle. 
while those lower than $88^{\circ}$ were valgus angles and those greater than $92^{\circ}$ were varus angles.

\section{Statistical Analysis}

All statistical analyses were performed using Statistical Package for Social Sciences version 16.0 for Windows (SPSS Inc., Chicago, IL, USA). Descriptive statistics were used to obtain frequencies, means and standard deviations, as appropriate. To compare the accuracy of the two tibial guide techniques (extramedullary versus intramedullary), we performed comparison analysis for mean $( \pm$ SD) TCA, TCA range (normal, valgus or varus) and alignment (normal/abnormal) between the two techniques. Means were compared using independent $t$-test. Proportions were compared using either chisquare $\left(X^{2}\right)$ test or Fisher's exact, as appropriate. Significance level was considered for a $\mathrm{p}$-value $<0.05$.

\section{Results}

A total of 60 patients ( 88 knees) were included in the current study. 28 were allocated to the intramedullary group. These comprised 25 female and three male, with a mean age \pm standard deviation (SD) of $68.5 \pm 8.7$ years. In the extramedullary group, there were 32 patients, of whom 23 were female and nine male, with a mean age \pm SD of $61.7 \pm 10.3$ years. In the intramedullary group, $28(73.7 \%)$ cases were unilateral and $10(26.3 \%)$ were bilateral. While in the extramedullary group 31 (62\%) cases were unilateral and 19 (38\%) were bilateral (Table 1).
The mean tibial component angle (TCA) \pm SD among the intramedullary group was $91.22 \pm 2.74$, while in the extramedullary group was $91.95 \pm 2.34$ ( $p$ $=0.184)$. The normal TCA values was found in $52.6 \%$ of the intramedullary group compared to $48 \%$ in the extramedullary group $(p=0.188)$, and the varus TCA was common in both groups (Table 2). The distribution of TCA is shown in (Fig. 2).

There was no statistically significant difference between the two groups with regard to the accuracy of the normal tibial component alignment.

\section{Discussion}

The long term results of TKR are influenced by different factors, which are related to the patient, implant, and surgical technique. Regarding the technique, the tibial component alignment is believed to be a key factor for the survivorship of total knee arthroplasty procedures. Although both intramedullary and extramedullary tibial guides are suitable for most of the knees, there is still much controversy about which technique is better for tibial cutting. Both techniques have disadvantages and limitations $s^{[1,6,8]}$, where the extra medullary are unreliable in patients with abnormal anatomy of the ankle and an excess of soft tissue, and the intramedullary are inappropriate when there is excessive tibial bowing, or retained hardware obliterating the medullary canal, and increased risk of fatty embolism. A review of the literatures has shown no significant consensus among authors about whether the intramedullary or

Table 1. Baseline characteristics of patients $(n=60)$ and total knee replacement $(n=88)$.

\begin{tabular}{|l|l|c|c|c|}
\hline \multicolumn{2}{|c|}{ Parameter } & Total & Intramedullary & Extramedullary \\
\hline \multicolumn{2}{|c|}{ Age $($ mean \pm SD $)(n=60)$} & $65.37 \pm 9.99$ & $68.5 \pm 8.7$ & $61.7 \pm 10.3$ \\
\hline \multirow{2}{*}{ Gender } & Male & $12(20 \%)$ & $3(25.0 \%)$ & $9(75.0 \%)$ \\
\cline { 2 - 5 } & Female & $48(80 \%)$ & $25(52.1 \%)$ & $23(47.9 \%)$ \\
\hline \multirow{2}{*}{ Diagnoses } & Primary Gonarthrosis & $82(93.2 \%)$ & $36(43.9 \%)$ & $46(56.1 \%)$ \\
\cline { 2 - 5 } & Other & $6(6.8 \%)$ & $2(33.3 \%)$ & $4(66.7 \%)$ \\
\hline \multirow{2}{*}{ Site } & Unilateral & $59(67.0 \%)$ & $28(73.7 \%)$ & $31(62.0 \%)$ \\
\cline { 2 - 5 } & Bilateral & $29(33.0 \%)$ & $10(26.3 \%)$ & $19(38.0 \%)$ \\
\hline
\end{tabular}

Table 2. Tibial component angle (TCA) in both groups $(n=88)$.

\begin{tabular}{|c|c|c|c|c|c|}
\hline \multicolumn{2}{|c|}{ Prosthesis Alignment } & Total $(\mathbf{n}=\mathbf{8 8})$ & $\begin{array}{c}\text { Intramedullary } \\
\mathbf{( 3 8 = 1 0 0 \% )}\end{array}$ & $\begin{array}{c}\text { Extramedullary } \\
\mathbf{( 5 0 = 1 0 0 \% )}\end{array}$ & p-Value \\
\hline \multirow{2}{*}{ TCA Range } & TCA $($ Mean \pm SD) & $\mathbf{9 1 . 6 3} \pm \mathbf{2 . 5 3}$ & $91.22 \pm 2.74$ & $91.95 \pm 2.34$ & $.184^{*}$ \\
\cline { 1 - 5 } & Normal $\left(88-92^{\circ}\right)$ & $\mathbf{4 4 ( 5 0 \% )}$ & $20(52.6 \%)$ & $24(48.0 \%)$ & \\
\cline { 2 - 5 } & Valgus $\left(<88^{\circ}\right)$ & $\mathbf{7 ( 8 . 0 \% )}$ & $5(13.2 \%)$ & $2(4.0 \%)$ & .188 \\
\cline { 2 - 5 } & Varus $\left(>92^{\circ}\right)$ & $\mathbf{3 7 ( 4 2 . 0 \% )}$ & $13(34.2 \%)$ & $24(48.0 \%)$ & \\
\hline
\end{tabular}

TCA = Tibial component angle; "Independent "student's" t-test 


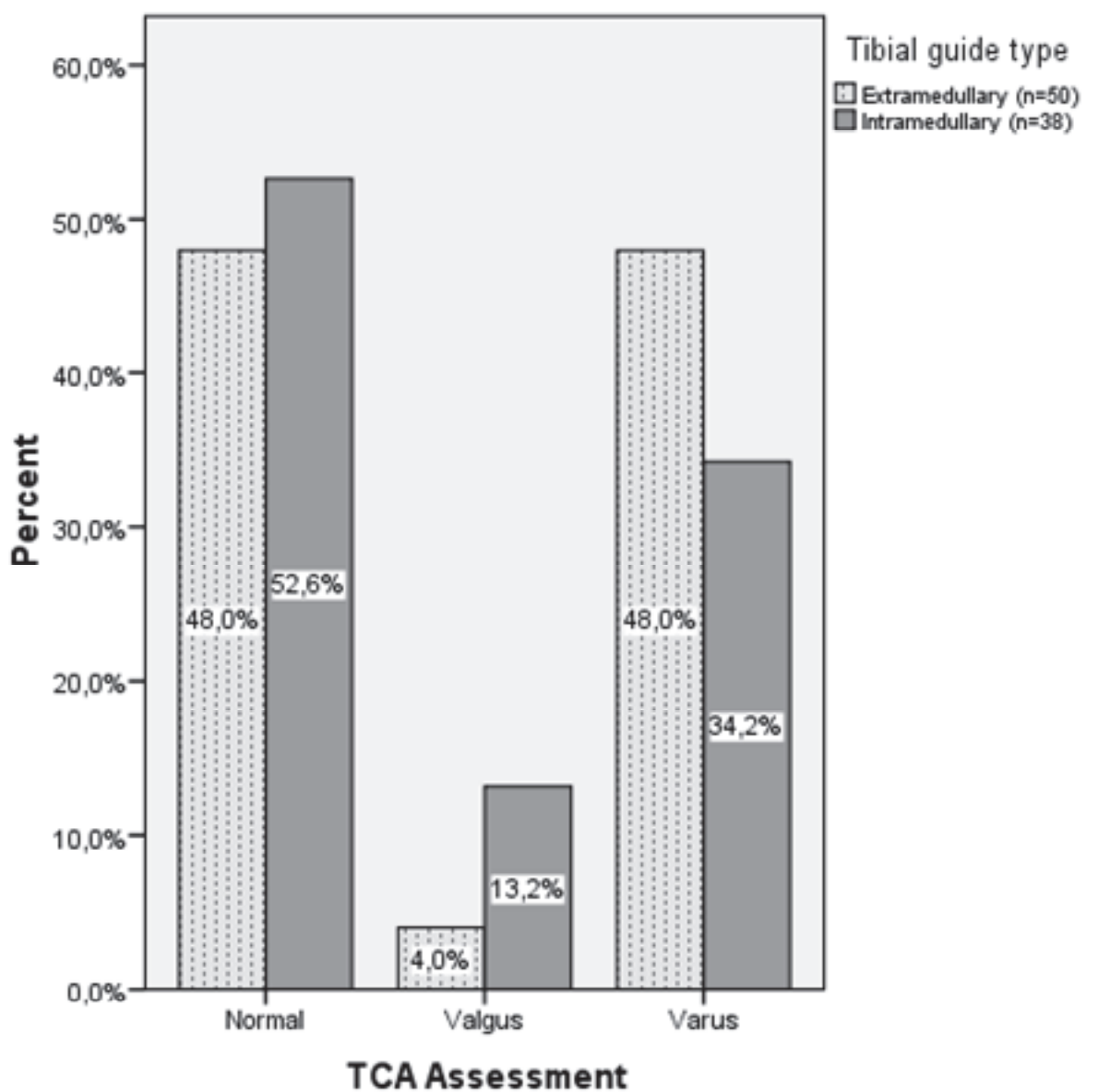

Figure 2. The distribution of tibial component angle (TCA).

exramedullary system is superior ${ }^{[1,8-11]}$, which is similar to the findings of our study.

Alongside the already used extramedullary system, the intramedullary tibial cutting guide system had been introduced at our institution two years prior seeking adequate alignment. We conducted the current study with aim to compare the accuracy of both systems and to discern whether one is superior to the other. Our study showed a slight but not statistically significant difference between intra- and extramedullary guides in the alignment of the tibial component, with neither system demonstrating a clear superiority. The accuracy rate of both guides in our study are comparable to those obtained by Bruno et al. ${ }^{[6]}$ But it is lower than those found in the study of Reed et al. ${ }^{[1]}$, particularly the intramedullary guide, where he recommends the guide rod to pass to the distal epiphyseal scar which will more likely improve the alignment. In our cases we passed the guide rod to a level just to the isthmus (per manufacturer instructions). Our results could be explained by the fact that the procedures were performed by different surgeons (both experienced and under training) which is likely to occur in a teaching hospital, as is the case in our university hospital.

Astudy involving British orthopedic surgeons found that $75.6 \%$ prefer extramedullary and $20.3 \%$ prefer intramedullary for tibial alignment, with the remainder using both ${ }^{[12]}$. Rottman et al. ${ }^{[4]}$ found no difference between intra- and extramedullary alignment in TKR in a retrospective series of 55 patients. Lozano et al. ${ }^{[0]}$ performed a study in severely obese patients and found no difference in the tibial component alignment between intra-and extramedullary guides. Also, similar results where no significant difference in the alignment of the tibial component and survivorship between the intra- and extramedullary systems were found in another two studies conducted by El Nahas et al. ${ }^{[13]}$ in 2013, and Bruno et al. ${ }^{[6]}$ in 2015. However, Reed et al., 
Intramedullary versus Extramedullary Tibial Cutting Guides in Total Knee Procedures...

L.A. Abumunaser et al.

in a randomized prospective trial, has shown that the intramedullary was superior to the extramedullary guide in the alignment of the tibial component ${ }^{[1]}$. The same findings were obtained by Cashman et al. in a study conducted in $2011^{[14]}$.

So, the debate between the intramedullary and extramedullary tibial cutting systems continues and orthopedic surgeons remain at liberty to utilize their most familiar technique.

A limitation of our study is the sample size, particularly in the intramedullary group, where a larger number of cases of this group would improve the statistical power of the study.

In conclusion, our findings have shown no difference between the intramedullary and extramedullary tibial cutting guides, and corroborate the utility of both techniques, intra-and extra medullary guides, in correct alignment of the tibial component in TKR procedures, considering the disadvantages and limitations of each system.

\section{Conflict of Interest}

The author has no conflict of interest.

\section{Disclosure}

The author did not receive any type of commercial support either in forms of compensation or financial for this study. The author has no financial interest in any of the products or devices, or drugs mentioned in this article.

\section{Ethical Approval}

Obtained.

\section{References}

[1] Reed MR, Bliss W, Sher JL, Emmerson KP, Jones SM, Partington PF. Extramedullary or intramedullary tibial alignment guides: a randomized, prospective trial of radiological alignment. J Bone Joint Surg (Br) 2002; 84-B(6): 858-860

[2] Rand JA, Trousdale RT, Ilstrup DM, Harmsen WS. Factors affecting the durability of primary total knee prostheses. J Bone Joint Surg Am 2003; 85-A(2): 259-265.

[3] MacDonald W, Styf J, Carlsson LV, Jacobsson CM. Improved tibial cutting accuracy in knee arthroplasty. Med Eng Phy 2004; 26(9): 807-812.
[4] Rottman SJ, Dvorkin M, Gold D. Extramedullary versus intramedullary tibial alignment guides for total knee arthroplasty. Orthopedics 2005; 28(12): 1445-1448.

[5] Parratte S, Pagnano MW, Trousadale RT, Berry DJ. Effect of postoperative mechanical axis alignment on the fifteenyear survival of modern, cemented total knee replacement. J Bone Joint Surg Am 2010; 92(12): 2143-2149.

[6] da Rocha Moreira Rezende B, Fuchs T, Nishi RN, Hatem MA, da Silva LM, Fuchs R, de Alencar PG. Alignment of the tibial component in total knee arthroplasty procedures using an intramedullary or extramedullary guide: double-blind randomized prospective study. Rev Bras Ortop 2015; 50(2): 168-173.

[7] Mason JB, Fehring TK, Estok R, Banel D, Fahrbach K. Metaanalysis of alignment in computer-assisted total knee arthroplasty surgery. J Arthroplasty 2007; 22(8): 10971106.

[8] Naser FA. Intramedullary versus extramedullary alignment guide for the accurate sagittal tibial prosthesis alignment in total knee replacement arthroplasty. J Fac Med Baghdad 2013; 55(3): 210-213.

[9] Lozano LM, Segur JM, Maculé F, Núñez M, Torner P, Castillo F, Suso S. Intramedullary versus extramedullary tibial cutting guide in severely obese patients undergoing total knee replacement: a randomized study of 70 patients with body mass index > $35 \mathrm{~kg} / \mathrm{m}^{2}$. Obes Surg 2008; 18(12): 1599-1604.

[10] Karade V, Ravi B, Agarwal M. Extramedullary versus intramedullary tibial cutting guides in megaprosthetic total knee replacement. J Orthop Surg Res 2012: 7: 33.

[11] Berend ME, Ritter MA, Meding JB, Faris PM, Keating EM, Redelman R, Faris GW, Davis KE. Tibial component failure mechanisms in total knee arthroplasty. Clin Ortho Relat Res 2004; (428): 26-34.

[12] Phillip AM, Gddard NJ, Tomlinson JE. Current techniques in total knee replacement: results of a national survey. Ann R Coll Surg Engl 1996; 78(6): 515-520.

[13] El Nahas MW, Nwachku I, Khan K, Gaber A, Hodgkinson J. Tibial alignment in total knee replacement surgery, intramedullary alignment versus extramedullary alignment a blinded single surgeon study. Open Bone J 2013; 5: 9-11.

[14] Cashman JP, Carty FL, Synnott K, Kenny PJ. Intramedullary versus extramedullary alignment of the tibial component in the triathlon knee. J Orthop Surg Res 2011; 6: 44. 


\title{
مقارنة طريقة داخل نخاع العظم بخارج نخاع العظم لقطع عضمة القصبه في عمليات مفصل الركبه الصناعيه: خبرتنا في مستشفى جامعة الملك عبدالعزيز بالمملكه العربيه السعوديه
}

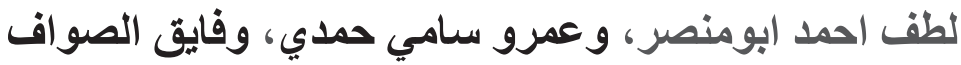

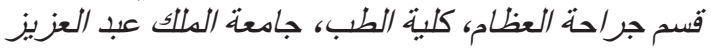 \\ جلة ـ المهلكة العربية السعودية
}

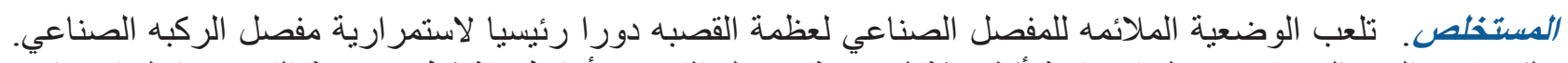

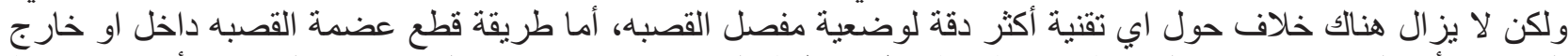

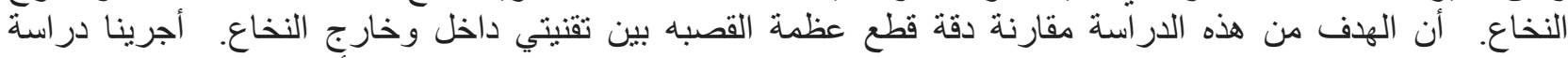

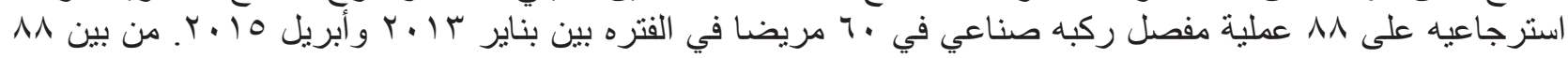

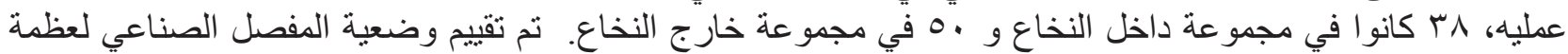

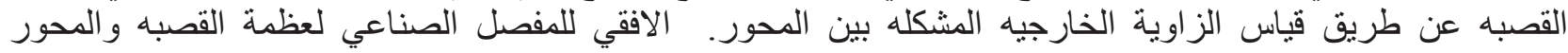

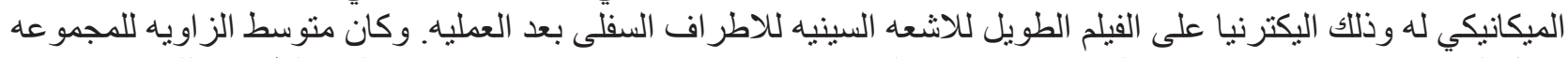

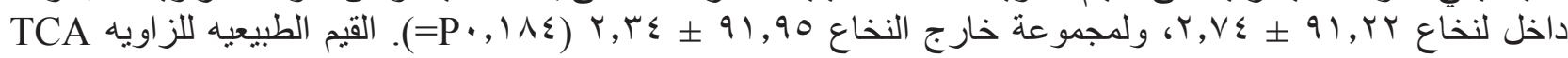

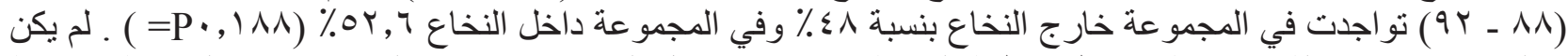

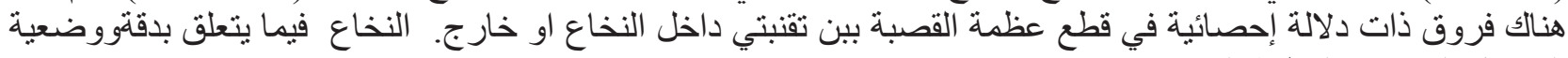
المفصل الصناعي لعظمة القصبا. 